\title{
Rapid Determination of L-carnitine in Infant and Toddler Formulas by Liquid Chromatography Tandem Mass Spectrometry
}

\author{
Jang-Hyuk Ahn ${ }^{1}$, Byung-Man Kwak², Jung-Min Park, Na-Kyeoung Kim, and Jin-Man Kim* \\ Department of Food Science and Biotechnology of Animal Resources, Konkuk University, Seoul 143-701, Korea \\ ${ }^{1}$ KOTITI Testing \& Research Institute, Seongnam 462-807, Korea \\ ${ }^{2}$ Food Safety Center, Research and Development Institute, Namyang Dairy Co., Ltd., Gongju 339-914, Korea
}

\begin{abstract}
A rapid and simple analytical method for L-carnitine was developed for infant and toddler formulas by liquid chromatography tandem mass spectrometry (LC-MS/MS). A $0.3 \mathrm{~g}$ of infant formula and toddler formula sample was mixed in a $50 \mathrm{~mL}$ conical tube with $9 \mathrm{~mL}$ water and $1 \mathrm{~mL} 0.1 \mathrm{M}$ hydrochloric acid $(\mathrm{HCl})$ to chemical extraction. Then, chloroform was used for removing a lipid fraction. After centrifuged, L-carnitine was separated and quantified using LC-MS/MS with electrospray ionization (ESI) mode. The precursor ion for L-carnitine was $\mathrm{m} / \mathrm{z} 162$, and product ions were $\mathrm{m} / \mathrm{z} 103$ (quantitative) and $\mathrm{m} / \mathrm{z} 85$ (qualitative), respectively. The results for spiked recovery test were in the range of $93.18-95.64 \%$ and the result for certified reference material (SRM 1849a) was within the range of the certificated values. This method could be implemented in many laboratories that require time and labor saving.
\end{abstract}

Keywords: L-carnitine, LC-MS/MS, analytical method, infant formula, toddler formula

\section{Introduction}

Carnitine is a very important nutritional ingredient included in infant and toddler formula. In particular, Lcarnitine among different forms of carnitine is also called vitamin Bt and carnitine utilized for food generally means L-carnitine (Steiber et al., 2004). Meat and dairy products are the main dietary supply source of L-carnitine, and normally carrying L-carnitine is essential for the smooth function of cardiac muscle, skeletal muscle, and many different tissues. It is indicated on the products with being added to the internationally produced sold formulated milk powder and infant and toddler formula as nutritional supplement ingredients, owing to this dietetic value and necessity. L-carnitine plays a role in helping decompose fat in the human body. Therefore, in case it is insufficient, energy produced in decomposing fatty acid is not generated, as fatty acid is not decomposed well (Olpin, 2005). For this reason, carnitine is much used as drug or food additives helpful to a diet. Besides, it plays a role in eliminating toxic substances from cell. In case of infant, the

\footnotetext{
*Corresponding author: Jin-Man Kim, Department of Food Science and Biotechnology of Animal Resources, Konkuk University, Seoul 143-701, Korea. Tel: +82-2-450-3688, Fax: +822-455-1044, E-mail: jinmkim@konkuk.ac.kr
}

activity of enzyme necessary for the last step of carnitine synthesis is only $12 \%$ of normal adult, and reaches the level of $30 \%$ of adult at 2-6 years old. Only if they are approximately 15 years old, the activity of carnitine reaches the level of adult. Hence ingestion through breast milk or infant and toddler formula from the outside is essential (Olpin, 2005).

L-carnitine is an amphoteric ion, and is a polar non-volatile compound without chromospheres. It can be analyzed with high-performance liquid chromatography (HPLC) or gas chromatography (GC) (Gong-Xin and Terry, 2000; Sowell et al., 2011). In case of HPLC, in being detected after carnitine is derivatized into bromophenacyl ester, an organic acid acts as interfering substance. Accordingly, limit of quantitation (LOQ) is shown to be high. In case of analysis with gas chromatography-mass spectrometry (GC-MS), after carrying out alkaline hydrolysis, methyl ester is made from free acid, or base is used as catalyst, and then cyclization is carried out, and then demethylated derivative is detected (Vogt and Seim, 1996). However, there are disadvantages of long chromatography analysis time and complicated sample preparation process in derivatization.

There is a method that can carry out the quantitative analysis of L-carnitine by utilizing the choline test method for the formulated milk powder and milk as an offi- 
cial analytical method (AOAC Official Method 999.14, 2003). And simultaneous analysis method utilizing liquid chromatography-mass spectrometry (LC-MS) of free carnitine and total choline content was published in AOAC official journal (Andrieux et al., 2008). Besides, a method through liquid chromatography-tandem mass spectrometry (LC-MS/MS) instrumental analysis was also presented (Starkey et al., 2008).

AOAC official test method and a method printed in the journal is accurate and precise, and is a close examination method utilizing up-to-date instrument, LC-MS/MS, and is a method suitable for examining a very small amount of L-carnitine. However, sample preparation of emulsified foods such as infant formulas is not easy. In general, sample preparation process of emulsified foods goes through alkali decomposition or fat-free process. And this was not considered in the previous paper of L-carnitine analysis. This study aims at introducing sample preparation method in consideration of the matrix characteristics of formulated milk powder, and aims at developing a simple test method that requires a smaller amount of test materials and time than the conventional method. Besides, it is intended to improve AOAC journal method by the precise instrumental analysis that has simple sample preparation method and utilizes LC-MS/MS.

\section{Materials and Methods}

\section{Standard, Samples, and reagents}

L-carnitine (Levocarnitine, Cat. No. 1359903) was purchased from the US Pharmacopeial Convention (USP, USA) for use as the reference standard material. Purity was $99.9 \%(0.999 \mathrm{mg} / \mathrm{mg})$. A stock solution of $1000 \mu \mathrm{g} /$ $\mathrm{mL}$ L-carnitine was dissolved in water, and diluted to the required concentrations of $1,5,10,25$, and $50 \mathrm{ng} / \mathrm{mL}$ to make the standard working solutions.

The infant and toddler formulas used in this study were purchased from a local market and stored at $4^{\circ} \mathrm{C}$. A certified reference material (CRM), infant formula SRM 1849a (NIST, USA), was used in the recovery tests to develop the method. The amount of L-carnitine in SRM $1849 \mathrm{a}$ was $136 \pm 14 \mathrm{mg} / \mathrm{kg}$ (coverage factor, $k=2.00$ ). Heptafluorobutyric acid (HFBA) was purchased from SigmaAldrich (USA) and $0.1 \mathrm{M}$ hydrochloric acid $(\mathrm{HCl})$ was purchased from Junsei Chemical (Japan). Water, methanol, and chloroform for HPLC grade were purchased from Merck (Germany). Ultrapure water was obtained using a Banstead Diamond TII system (USA). The distilled water had a resistance of $18.0 \mathrm{M} \Omega$.

\section{Sample preparation}

A method for sample preparation was based on the previous study (Starkey et al., 2008), however, additional techniques were used for protein removal through the acid hydrolysis and lipid removal through the organic solvent extraction. Samples containing $0.3 \mathrm{~g}$ was placed in $50 \mathrm{~mL}$ conical tubes and dissolved in $9 \mathrm{~mL}$ of distilled water and $1 \mathrm{~mL}$ of $0.1 \mathrm{M} \mathrm{HCl}$. The $\mathrm{pH}$ for sample solution adjusted from control (6.6-6.8) to 4.0, this is in order to remove a casein which makes up about $80 \%$ of the milk protein fraction. After the $\mathrm{pH}$ was lowered than 4.6 (isoelectric point of casein), it was intended to isoelectric protein precipitation (Lovrien et al., 1997). After the addition of 10 $\mathrm{mL}$ of chloroform for removing a lipid fraction (Sullivan and Carpenter, 1993), the solutions were covered with a screw cap and vigorously mixed for 1 min using a vortex mixer at maximum speed. The tube was then centrifuged for $5 \mathrm{~min}$ at $3000 \mathrm{rpm}$ at $4^{\circ} \mathrm{C}$. An aqueous upper layer of the solution was filtered by a $0.45 \mu \mathrm{m}$ polytetrafluoroethylene (PTFE) filter, and transferred to a vial for instrumental analysis.

\section{Operating conditions}

The operating conditions for instrumental analysis were determined by analogy with previous reports using LCMS/MS (Starkey et al., 2008). An Agilent 1200 HPLC system (Agilent, USA) equipped with a Zorbax Eclipse $\mathrm{C}_{8}(4.6 \mathrm{~mm} \times 150 \mathrm{~mm}, 5 \mu \mathrm{m})$ reverse-phase column and a 6410 triple quadrupole LC/MS tandem MS system were used for analysis of L-carnitine. The mobile phase was composed of $0.1 \%$ HFBA in water solution $(90 \%)$ and $0.1 \%$ HFBA in methanol solution $(10 \%)$ for isocratic flow. Flow rate was $0.3 \mathrm{~mL} / \mathrm{min}$, column temperature was $30^{\circ} \mathrm{C}$, and injection volume was $10 \mu \mathrm{L}$. Solvents for HPLC grade were filtered by $0.45 \mu \mathrm{m}$ membrane and used after ultrasonic degassing. The specific conditions for LC-MS/ MS used for the analysis are shown in Table 1.

\section{Validation of the method}

The developed method was validated by the AOAC guidelines for single laboratory validation of chemical methods (AOAC International, 2002). For method validation, there were evaluated the following 5 parameters; linearity, limit of detection (LOD), limit of quantification (LOQ), method detection limit (MDL), and results for recovery test. The linearity of the method was characterized by the average coefficient of determination $\left(r^{2}\right)$ and was calculated using five consecutive standard curves. The LOD and LOQ were determined by diluting an L- 
Table 1. Liquid chromatography-tandem mass spectrometry conditions for L-carnitine (a) LC

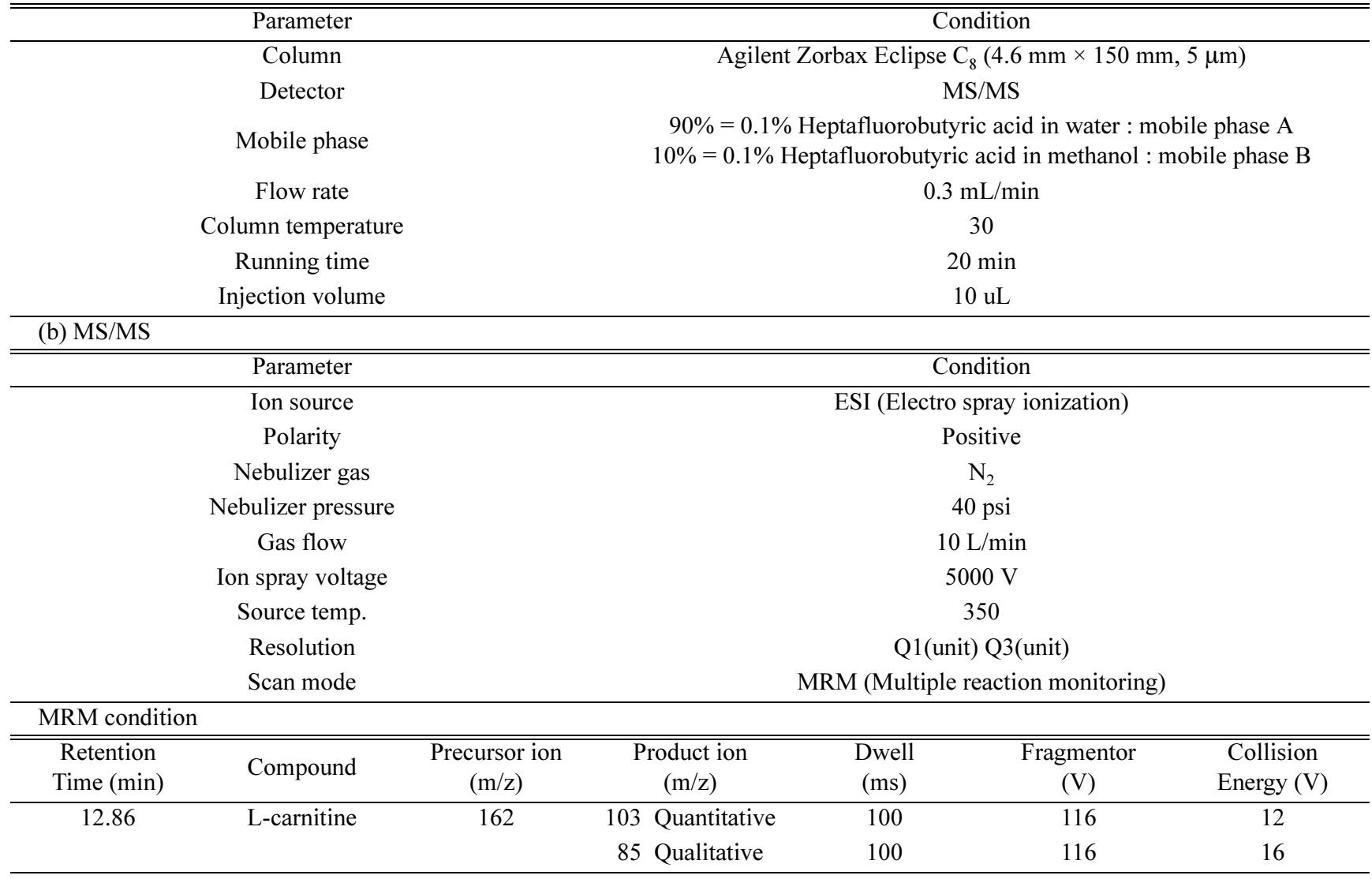

carnitine standard working solutions to obtain signal to noise ratios of $\sim 3: 1$ for $\mathrm{LOD}$ and $\sim 10: 1$ for LOQ. MDL was determined by multiplying the solvent volume $(\mathrm{mL})$ of the LOD and dividing by the sample amount $(\mathrm{g})$. The recovery tests of L-carnitine were carried out by spiking test with infant formula sample, and confirmation of certificated value for SRM 1849a. For the spiking test, spiked levels of infant formula was $50 \mathrm{mg} / \mathrm{kg}$ for $0.3 \mathrm{~g}$ of sample and the results of the quantitative analysis were compared to that obtained for samples without the standard solution.

\section{Monitoring test}

The three types of infant formulas (milk-based powder, milk-based liquid and cereal-based powder) and toddler formula (milk-based powder) were tested for the determination of L-carnitine contents. Total 32 samples were used for monitoring test. All samples were purchased from a local market and stored at room temperature.

\section{Results and Discussion}

\section{Optimization for $\mathrm{pH}$ in sample extract}

For sample preparation method, it was referred to L- carnitine method (Starkey et al., 2008) of formulated milk powder and raw materials, which is introduced in AOAC journal. However, there were several difficulties with rapid accurate sample preparation. First, the method of AOAC journal uses L-carnitine-methyl-d3 $\mathrm{HCl}$, isotopically labeled internal standard. However, it was thought that there was difficulty in using this internal standard in the testing \& research institute and industrial circles due to high price, restriction on the import of radioactive isotope, and so on. Second, the method presented by the previous study was a very simple method that had sample preparation process where $2 \mathrm{~g}$ of sample was taken, and then it was dissolved in water of $500 \mathrm{~mL}$, and PTFE filter treatment was carried out, and then instrumental analysis was made. However, as this doesn't have any deproteinization and fat-free process, there is possibility of having a bad effect due to the accumulation of contamination in the instrument in case of repeated analysis. For the above reason, we aimed at the test method that showed high recovery without using internal standard, and carried out the development of test method by introducing fat-free technology through organic solvent treatment and deproteinization through acid treatment in order to prevent col- 


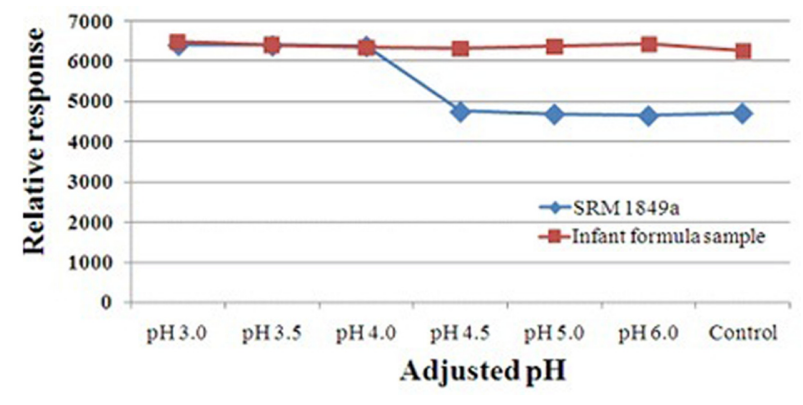

Fig. 1. Contents of L-carnitine in the extracted solution by pH adjusting in the range of $3.0 \sim$ control. Control $\mathrm{pH}$ was 7.6 (SRM 1849a), and 6.8 (infant formula sample), respectively.

umn and detector from being contaminated. Isoelectric protein precipitation using acid treatment was attempted for deproteinization. Fig. 1 showed the relative response results of L-carnitine detected in the final solution according to each $\mathrm{pH}$ after deproteinization treatment. In the test results, infant formula sample didn't show large difference in the relative response of L-carnitine from the $\mathrm{pH}$ 3.0 to the control pH 6.8. However, in SRM 1849a, no difference was shown in the response from $\mathrm{pH} 3.0$ to 4.0 , but it was observed that L-carnitine content went down to the level of $75 \%$ from $\mathrm{pH} 4.5$ or over. In case of SRM $1849 \mathrm{a}$, the amount of $0.1 \mathrm{M} \mathrm{HCl}$ projected in order to adjust $\mathrm{pH}$ was $\mathrm{pH} 3.0=1.7 \mathrm{~mL}, \mathrm{pH} 3.5=1.4 \mathrm{~mL}$, $\mathrm{pH} 4.0$ $=1 \mathrm{~mL}, \mathrm{pH} 4.5=0.8 \mathrm{~mL}, \mathrm{pH} 5.0=0.6 \mathrm{~mL}, \mathrm{pH} 6.0=0.3$ $\mathrm{mL}$, and control $=\mathrm{pH} 7.6$ respectively. Besides, in case of randomly selected infant formula sample, the amount of $0.1 \mathrm{M} \mathrm{HCl}$ projected in order to adjust $\mathrm{pH}$ was $\mathrm{pH} 3.0=$ $1.6 \mathrm{~mL}$, pH $3.5=1.3 \mathrm{~mL}, \mathrm{pH} 4.0=1 \mathrm{~mL}, \mathrm{pH} 4.5=0.7$
$\mathrm{mL}, \mathrm{pH} 5.0=0.55 \mathrm{~mL}, \mathrm{pH} 6.0=0.25 \mathrm{~mL}$, and control $=$ $\mathrm{pH} 6.8$ respectively. Therefore, on the basis of this study, we judged that it was proper to adjust $\mathrm{pH}$ to 4.0 in case of infant and toddler formula sample preparation. And according to the test results, it was verified that $\mathrm{pH}$ was adjusted to the level of 4.0 in case $0.1 \mathrm{M} \mathrm{HCl} 1 \mathrm{~mL}$ was projected on the basis of sample $0.3 \mathrm{~g} /$ final volume 10 $\mathrm{mL}$.

\section{Optimization for mobile phase}

To the optimization of selectivity for L-carnitine, the ratio of $0.1 \%$ heptafluorobutyric acid in water solution (mobile phase A) to $0.1 \%$ heptafluorobutyric acid in methanol solution (mobile phase B) was changed from 0 to $100 \%$ in order to establish the optimum mobile phase condition of selected column (Zorbax Eclipse $\mathrm{C}_{8}, 4.6 \mathrm{~mm}$ $\times 150 \mathrm{~mm} \times 5 \mu \mathrm{m}$, Agilent). The results were shown in Fig. 2. When the ratio of mobile phase A to B was 90:10, the optimum condition where the specificity of substance subject to analysis was secured and the sensitivity of peak was the highest in the test results. After that time, tests were carried out in the above mobile phase condition.

\section{Linearity \& range}

L-carnitine content in infant and toddler formula was approximately $100 \mathrm{mg} / \mathrm{kg}$, and the range of certified value of SRM 1849a was $136 \pm 14 \mathrm{mg} / \mathrm{kg}$. In case of completing sample preparation with final volume of $10 \mathrm{~mL}$ in comparison with sample of $0.3 \mathrm{~g}$ proposed by this study, the range of expected calibration curve was at the level of 3$5 \mathrm{mg} / \mathrm{L}(\mathrm{ppm})$. However, linearity was not shown in measuring carnitine standard in case of high-concentration

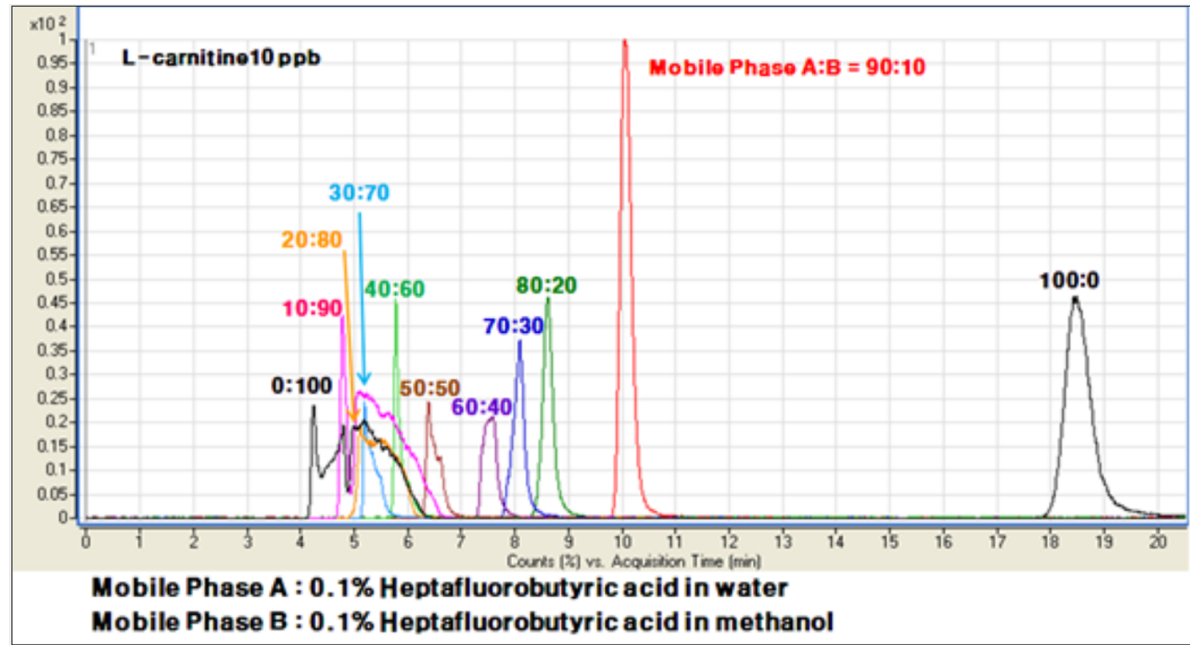

Fig. 2. Liquid chromatography-tandem mass spectrometry (LC-MS/MS) chromatograms when different mobile phases were used for L-carnitine analysis. 
-oanizine - 9 Levels, 9 Levels Used, 9 Points, 9 Points Used, 0 oCs

a) $\times 10^{5} y=-0.115961 \times x \hat{}^{2}+321.979468 \times x+2277.751038$

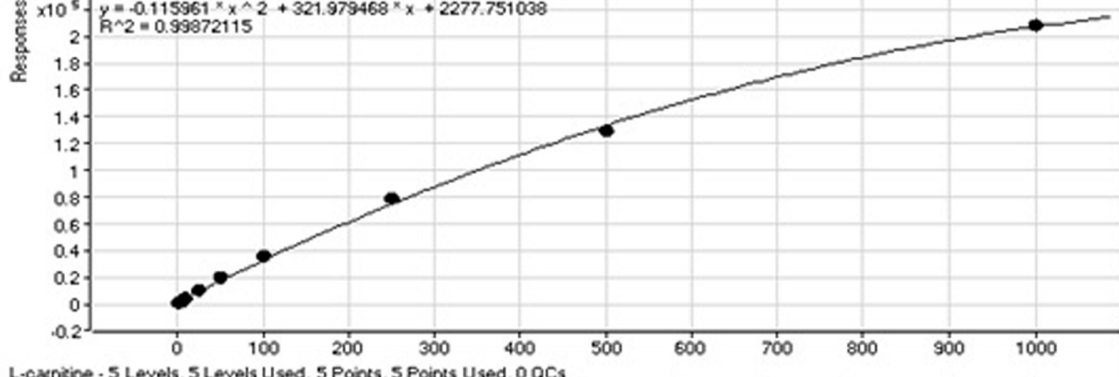

(b)

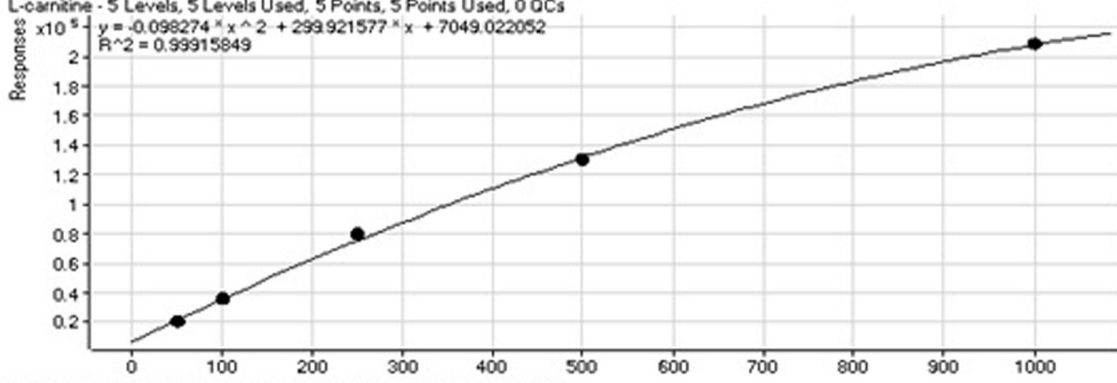

(c)

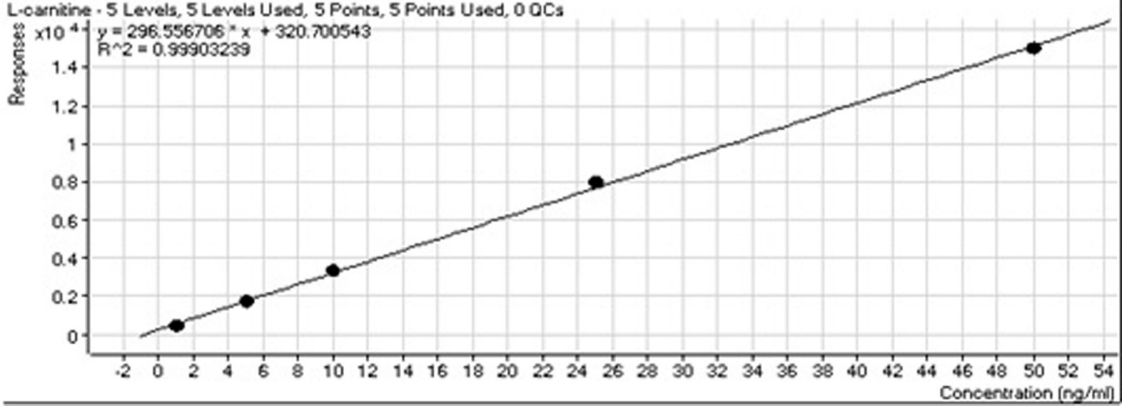

Fig. 3. Comparison of calibration curves for L-carnitine standard solutions; 9 points of 1, 5, 10, 25, 50, 100, 250, 500, and 1000 $\mu \mathrm{g} / \mathrm{L}$ (a), 5 points of $50,100,250,500$, and $1000 \mu \mathrm{g} / \mathrm{L}$ (b), 5 points of $1,5,10,25$, and $50 \mu \mathrm{g} / \mathrm{L}$ (c), respectively.

calibration curve in ppm unit. Therefore, the necessity of measurement with lowering calibration curve concentration and diluting final preparation solution came to the front. In order to establish the optimum calibration curve condition, carnitine standard was measured at 9 points within the range of $1-1,000 \mu \mathrm{g} / \mathrm{L}(\mathrm{ppb})$, and the section that showed linearity was observed in the range. The results were shown in Fig. 3. According to the test results, $r^{2}$ value was 0.9990 and linearity was shown in the section of $1,5,10,25$, and $50 \mu \mathrm{g} / \mathrm{L}$. And quadratic calibration curve was observed in the section of 50, 100, 250, 500 , and $1000 \mu \mathrm{g} / \mathrm{L}$. Therefore, in this test, we decided on $1-50 \mu \mathrm{g} / \mathrm{L}$ of calibration curve concentration, and decided that final solution was diluted 200 times in conformance with this, and then was used for instrumental analysis.

\section{Method validations}

Detection limit test, infant formula recovery test, and certified reference material SRM 1849a quantitative analysis were carried out in order to verify the validity of developed L-carnitine LC-MS/MS analytical method. The method was validated through comparison of quantitative analysis results with certified value. The test results showed that the limit of detection (LOD) was $0.05 \mu \mathrm{g} / \mathrm{L}$, and the limit of quantitation (LOQ) was $0.17 \mu \mathrm{g} / \mathrm{L}$, and method detection limit (MDL) was $0.57 \mathrm{mg} / \mathrm{kg}$. In case of recovery test, recovery was shown to be $93.18-95.64 \%$ and relative standard deviation was shown to be 1.93$2.74 \%$. Therefore, the result values were good. Besides, the carnitine content of SRM 1849a was measured to be $127.09 \mathrm{mg} / \mathrm{kg}$ and recovery of $93.38 \%$ was shown in case of being compared with $136 \mathrm{mg} / \mathrm{kg}$, median of certified value. From the above results, it was possible to judge that instrumental analysis condition and preparation method used in this study was valid. The specific validation factors were shown in Table 2.

In this study, the establishment of MS conditions was conducted by following the guidelines for the determination of L-carnitine specified by the European Community (EC) and the Codex Alimentarius Commission (CAC) 
Table 2. Validation factors and monitoring test for L-carnitine in certified reference material (SRM 1849a) and infant formula using liquid chromatography-tandem mass spectrometry analysis

\begin{tabular}{|c|c|c|c|c|c|}
\hline \multicolumn{2}{|l|}{ Recovery test } & \multirow{2}{*}{$\begin{array}{c}\text { Tested Value }(\mathrm{mg} / \mathrm{kg}) \\
127.09 \pm 1.67\end{array}$} & \multicolumn{2}{|l|}{ RSD (\%) } & Recovery (\%) \\
\hline \multicolumn{2}{|l|}{ SRM 1849a } & & \multicolumn{2}{|l|}{1.31} & $93.45 \pm 1.23$ \\
\hline \multirow{3}{*}{ Spiked sample } & $\mathrm{T}-1$ & $265.84 \pm 3.84$ & \multicolumn{2}{|l|}{2.74} & $93.18 \pm 1.54$ \\
\hline & $\mathrm{T}-2$ & $271.91 \pm 3.22$ & \multicolumn{2}{|l|}{2.53} & $95.64 \pm 1.45$ \\
\hline & $\mathrm{T}-3$ & $265.81 \pm 2.65$ & \multicolumn{2}{|l|}{1.93} & $95.31 \pm 2.03$ \\
\hline \multicolumn{2}{|l|}{ Samples } & Tested Value (mg/kg) & \multicolumn{2}{|l|}{ Samples } & Tested Value $(\mathrm{mg} / \mathrm{kg})$ \\
\hline \multirow{15}{*}{$\begin{array}{c}\text { Infant formula } \\
\text { (milk-based, powder) }\end{array}$} & $\mathrm{T}-1$ & 141.25 & \multirow{10}{*}{$\begin{array}{c}\text { Toddler formula } \\
\text { (milk-based, powder) }\end{array}$} & $\mathrm{T}-1$ & 191.28 \\
\hline & $\mathrm{T}-2$ & 111.18 & & $\mathrm{~T}-2$ & 137.27 \\
\hline & $\mathrm{T}-3$ & 138.77 & & $\mathrm{~T}-3$ & 130.51 \\
\hline & $\mathrm{T}-4$ & 133.58 & & $\mathrm{~T}-4$ & 124.96 \\
\hline & $\mathrm{T}-5$ & 104.18 & & $\mathrm{~T}-5$ & 106.78 \\
\hline & T-6 & 100.13 & & $\mathrm{~T}-6$ & 102.39 \\
\hline & $\mathrm{T}-7$ & 109.25 & & $\mathrm{~T}-7$ & 114.79 \\
\hline & $\mathrm{T}-8$ & 111.78 & & $\mathrm{~T}-8$ & 140.29 \\
\hline & $\mathrm{T}-9$ & 130.75 & & $\mathrm{~T}-9$ & 159.45 \\
\hline & $\mathrm{T}-10$ & 136.84 & & $\mathrm{~T}-10$ & 143.31 \\
\hline & $\mathrm{T}-11$ & 138.22 & \multirow{4}{*}{$\begin{array}{c}\text { Infant formula } \\
\text { (cereal-based, powder) }\end{array}$} & $\mathrm{T}-1$ & 142.03 \\
\hline & $\mathrm{T}-12$ & 149.88 & & $\mathrm{~T}-2$ & 126.45 \\
\hline & $\mathrm{T}-13$ & 139.82 & & $\mathrm{~T}-3$ & 117.56 \\
\hline & $\mathrm{T}-14$ & 138.15 & & $\mathrm{~T}-4$ & 184.02 \\
\hline & $\mathrm{T}-15$ & 129.25 & & & \\
\hline Samples & & Tested Value (mg/L) & & & \\
\hline \multirow{3}{*}{$\begin{array}{c}\text { Infant formula } \\
\text { (milk-based, liquid) }\end{array}$} & $\mathrm{T}-1$ & 20.89 & & & \\
\hline & $\mathrm{T}-2$ & 17.97 & & & \\
\hline & $\mathrm{T}-3$ & 15.60 & & & \\
\hline$r^{2}$ & & 0.9990 & Linear Regression & & $y=296.56 x+320.70$ \\
\hline LOD $(\mu \mathrm{g} / \mathrm{L})$ & & 0.05 & Range & & $1 \sim 50 \mu \mathrm{g} / \mathrm{L}$ \\
\hline LOQ $(\mu \mathrm{g} / \mathrm{L})$ & & 0.17 & & & \\
\hline MDL (mg/kg) & & 0.57 & & & \\
\hline
\end{tabular}

(Commission decision of 12 August 2002, 2002; Codex guideline, 2007). The precursor ion for L-carnitine corresponded to $162 \mathrm{~m} / \mathrm{z}$, the product qualitative ions was 85 , and the quantitative ion was $103 \mathrm{~m} / \mathrm{z}$, respectively. Under these conditions, by comparison with the standard deviation of the relative response values, the results for SRM 1849a and infant formula samples were within the acceptable range.

\section{Monitoring test for infant and toddler formulas}

A monitoring test was carried out for 32 samples of infant formula and toddler formula with SRM 1849a, international certified reference material. The results of monitoring test were shown in Table 2. According to the results of the monitoring test, in case of powder form product, L-carnitine content was at the level of 100.13$191.28 \mathrm{mg} / \mathrm{kg}$. It was at the level of $15.60-20.89 \mathrm{mg} / \mathrm{L}$, in case of liquid form product. This was at the accurate level in comparison with content indicated on the product. Therefore, it was possible to verify that L-carnitine indi- cation management of infant and toddler formula placed on the Korean market was well accomplished. Quantity corresponding to appropriate sample volume of each food group was $0.3 \mathrm{~g}$ for all sample groups and it was quantity corresponding to sample volume included in calibration curve concentration established by the method. LC-MS/ MS chromatogram and mass spectrum for L-carnitine was shown in Fig. 4. The chromatograms and the mass spectrum showed that the standard solution, infant formula and SRM 1849a sample treated by the developed test method and standard solution.

\section{Conclusions}

A method for the determination of L-carnitine in infant and toddler formula was developed by using LC-MS/MS and simple pretreatment. A $0.3 \mathrm{~g}$ of infant formula sample was mixed in a $50 \mathrm{~mL}$ conical tube with $9 \mathrm{~mL}$ water and $1 \mathrm{~mL} 0.1 \mathrm{M} \mathrm{HCl}$ to chemical extraction. Then, chloroform was used for removing a lipid fraction. After cen- 
(a)
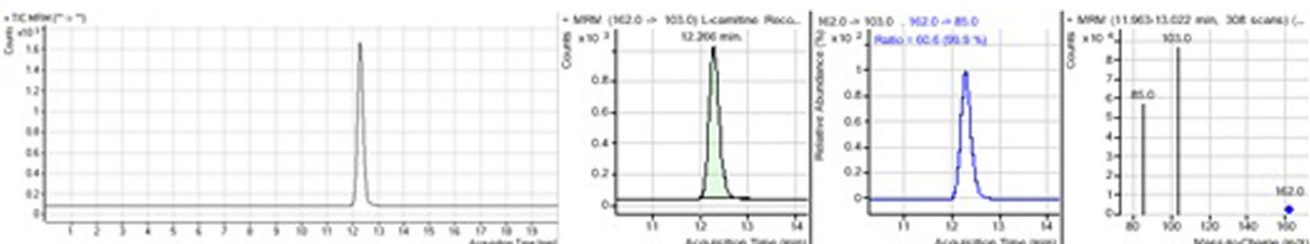

(b)
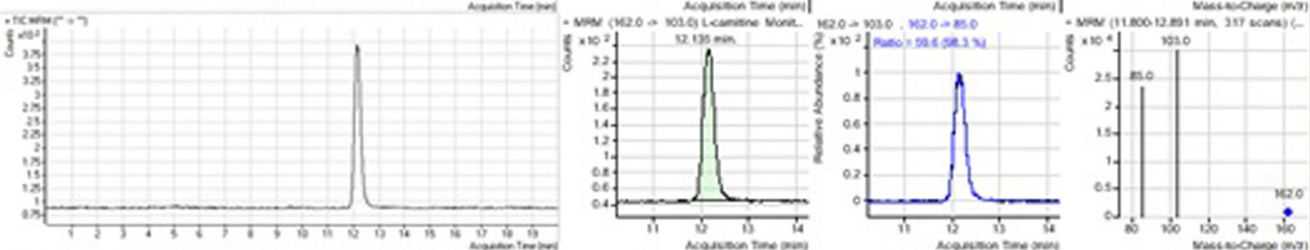

(c)
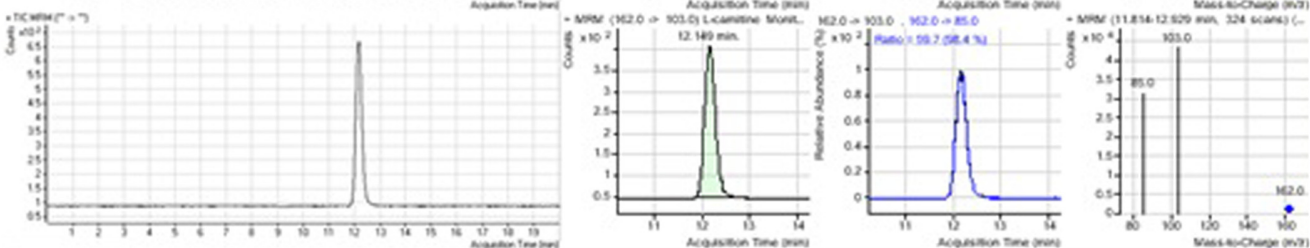

Fig. 4. Liquid chromatography-tandem mass spectrometry (LC-MS/MS) chromatograms of L-carnitine by the total ion current and multiple reaction monitoring (MRM) mode, with relative response ratios; L-carnitine standard solution (a), SRM 1849a (b), and Infant formula sample (c), respectively.

trifuged, L-carnitine was separated and quantified using LC-MS/MS with ESI mode. This procedure was applied to small sample weight, $\mathrm{pH}$ adjustment, and lipid elimination. Sample pretreatment time and labor were reduced, although the recovery test showed good results for infant formula sample. The precursor ion for L-carnitine was $\mathrm{m} /$ $\mathrm{z} 162$, and product ions were $\mathrm{m} / \mathrm{z} 103$ (quantitative) and $\mathrm{m} / \mathrm{z} 85$ (qualitative), respectively. The results for spiked recovery test were in the range of $93.18-95.64 \%$ with relative standard deviations between $1.93 \%$ and $2.74 \%$ and the result for certified reference material (SRM 1849a) was within the range of the certificated values. The developed method based on LC-MS/MS in MRM mode, following the described sample preparation, could be an accurate tool that could replace the official methods when time and labor need to be reduced. In addition, it could be expected that a beginner can easily perform the analysis work as the analysis time is short and the low level of proficiency is required for testers.

\section{Acknowledgements}

This paper was supported by a grant (13162 MFDS 016) from Ministry of Food and Drug Safety in 2013 and as part of Konkuk University's research support in 2013.

\section{References}

1. Andrieux, P., Kilinc, T., Perrin, C., and Campos-Giménez, E.
(2008) Simultaneous determination of free carnitine and total choline by liquid chromatography/mass spectrometry in infant formula and health-care products: single-laboratory validation. J. AOAC Int. 91, 777-785.

2. AOAC International (2002) AOAC Guidelines for Single Laboratory Validation of Chemical Methods for Dietary Supplements and Botanicals. Association of Official Analytical Chemists, Gaithersburg, MD, USA.

3. AOAC Official Method 999.14 (2003) Choline in Infant Formula and Milk to the Determination of Choline in Dietary Supplements. Enzymatic colorimetric method, Final Action 2003.

4. Codex guideline (2007) Draft Guidelines for the Design and Implementation of National Regulatory Food Safety Assurance Programs Associated with the Use of Veterinary Drugs in Food Producing Animals. Codex Alimentarius Commission, Rome, Italy.

5. Commission decision of 12 August 2002 (2002) Implementing council directive 96/23/EC concerning the performance of analytical methods and the interpretation of results. Official Journal of the European Communities, Lisbon, Portugal.

6. Gong-Xin, H. and Terry, D. (2000) Improved high-performance liquid chromatographic method for analysis of L-carnitine in pharmaceutical formulations. J. Pharmaceut. Biomed. 23, 315-321.

7. Lovrien, R. E. and Matulis, D. (1997) Selective precipitation of proteins. Curr. Protoc Protein Sci. 4, 1-36.

8. Olpin, S. E. (2005) Fatty acid oxidation defects as a cause of neuromyopathic disease in infants and adults. Clinical Laboratory 51, 289-306.

9. Sowell, J., Fuqua, M., and Wood, T. (2011) Quantification of total and free carnitine in human plasma by hydrophilic interaction liquid chromatography tandem mass spectrometry. $J$. 
Chromatogr. Sci. 49, 463-468.

10. Starkey, D. E., Denison, J. E., Seipelt, C. T., and Jacobs, W. A. (2008) Single-laboratory validation of a liquid chromatographic/tandem mass spectrometric method for the determination of free and total carnitine in infant formula and raw ingredient. J. AOAC Int. 91, 130-142.

11. Steiber, A., Kerner, J., and Hoppel, C. L. (2004) Carnitine: a nutritional, biosynthetic, and functional perspective. Mol. Aspects. Med. 25, 455-473.
12. Sullivan, D. M. and Carpenter, D. E. (1993) Methods of analysis for nutrition Labeling: Chapter 5 Lipid Analysis. Arlington, VA, USA, AOAC International 85-103.

13. Vogt, C. and Seim, H. (1996) HPLC and capillary electrophoresis in carnitine analysis. Carnitine: pathobiochemical basics and clinical applications: Carnitine symposium, Carnitine: pathobiochemical basics and clinical applications (pp. 85-96). Ponte Press, Bochum.

(Received 2014.8.21/Accepted 2014.9.28) 